BMC

Evolutionary Biology

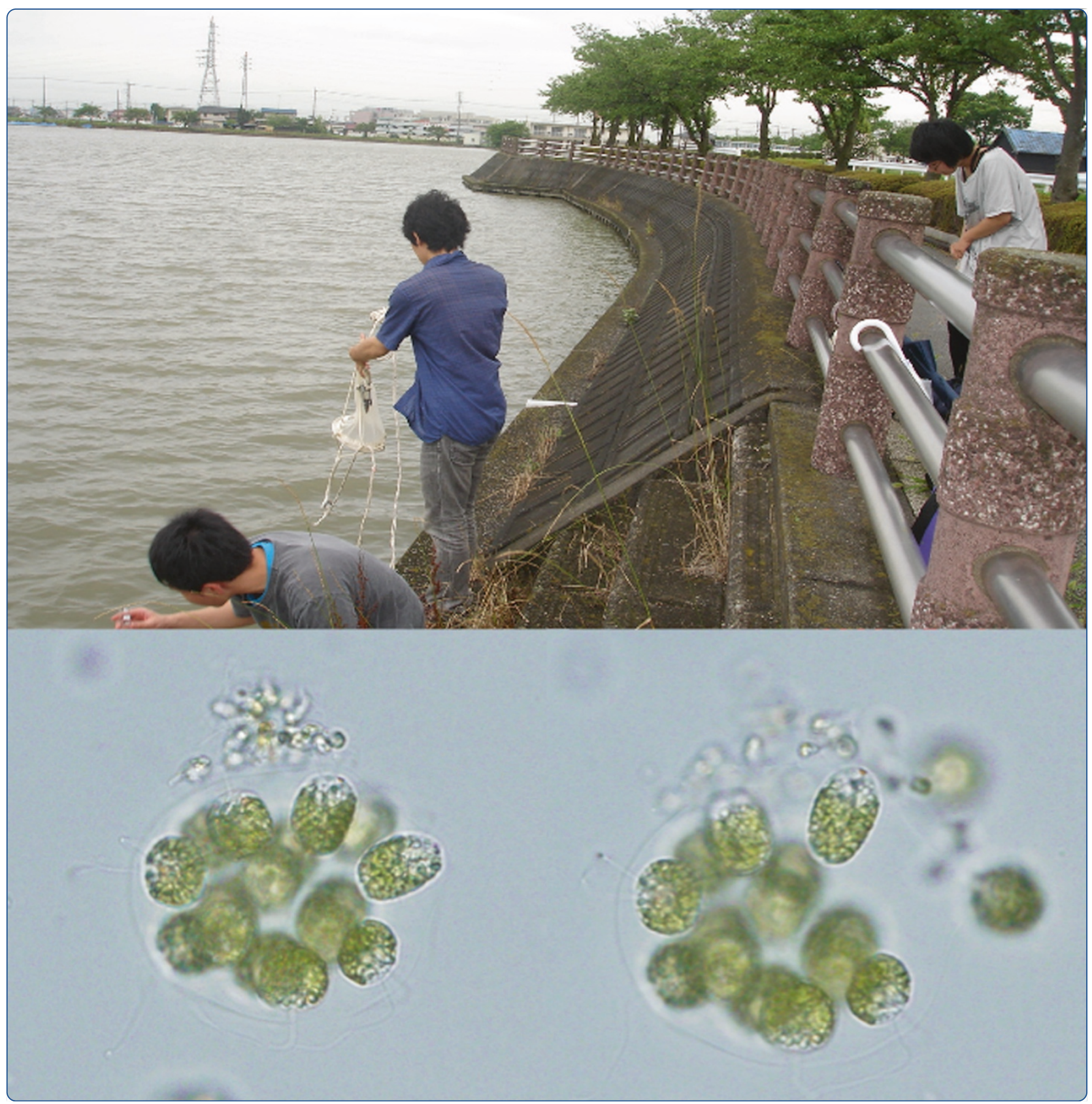

New "missing link" genus of the colonial volvocine green algae gives insights into the evolution of oogamy

Nozaki et al. 


\title{
New "missing link" genus of the colonial volvocine green algae gives insights into the evolution of oogamy
}

\author{
Hisayoshi Nozaki ${ }^{1 *}$, Toshihiro K Yamada ${ }^{1}$, Fumio Takahashi², Ryo Matsuzaki ${ }^{1}$ and Takashi Nakada ${ }^{3,4}$
}

\begin{abstract}
Background: The evolution of oogamy from isogamy, an important biological event, can be summarized as follows: morphologically similar gametes (isogametes) differentiated into small "male" and large "female" motile gametes during anisogamy, from which immotile female gametes (eggs) evolved. The volvocine green algae represent a model lineage to study this type of sex evolution and show two types of gametic unions: conjugation between isogametes outside the parental colonies (external fertilization during isogamy) and fertilization between small motile gametes (sperm) and large gametes (eggs) inside the female colony (internal fertilization during anisogamy and oogamy). Although recent cultural studies on volvocine algae revealed morphological diversity and molecular genetic data of sexual reproduction, an intermediate type of union between these two gametic unions has not been identified.

Results: We identified a novel colonial volvocine genus, Colemanosphaera, which produces bundles of spindle-shaped male gametes through successive divisions of colonial cells. Obligately anisogamous conjugation between male and female motile gametes occurred outside the female colony (external fertilization during anisogamy). This new genus contains 16- or 32-celled spheroidal colonies similar to those of the volvocine genera Yamagishiella and Eudorina. However, Colemanosphaera can be clearly distinguished from these two genera based on its sister phylogenetic position to the enigmatic flattened colonial volvocine Platydorina and external fertilization during anisogamy. Two species of Colemanosphaera were found in a Japanese lake; these species are also distributed in European freshwaters based on a published sequence of an Austrian strain and the original description of Pandorina charkowiensis from Ukraine.

Conclusions: Based on phylogeny and morphological data, this novel genus exhibits a missing link between Platydorina and the typical spheroidal colonial volvocine members such as Pandorina or Yamagishiella. Considering the external obligate anisogamy, oogamy evolution may have been preceded by the transition from external to internal fertilization during anisogamy within the volvocine green algae.
\end{abstract}

\section{Background}

The volvocine algae from unicellular Chlamydomonas to multicellular Volvox represent an "evolutionary time machine" model lineage to study the evolution of femalemale sexual dimorphism and multicellularity because they encompass the evolutionary ranges of vegetative and reproductive morphologies between these two extremes $[1,2]$. Based on chloroplast multigene phylogeny, a major evolutionary scenario within the lineage was resolved

\footnotetext{
* Correspondence: nozaki@biol.s.u-tokyo.ac.jp

'Department of Biological Sciences, Graduate School of Science, University of Tokyo, 7-3-1 Hongo, Bunkyo, Tokyo 113-0033, Japan

Full list of author information is available at the end of the article
}

ranging gradually from primitive unicellular organisms with conjugating gametes of identical size (isogamy) to the advanced multicellular spheroid with differentiation of male-female sexes (oogamy) such as Volvox [3-5]. The colonial volvocine algae show two types of gametic union: conjugation between isogametes outside the parental colonies (external fertilization during isogamy) and fertilization between small motile male gametes (sperm) and large female gametes (eggs) inside the female colony (internal fertilization during anisogamy and oogamy). Although recent cultural studies on the volvocine algae revealed morphological diversity and molecular genetic data 
of sexual reproduction [6-9], an intermediate between these two gametic unions has not been demonstrated.

The colonial volvocine algae include two morphologically unique organisms: Volvox sect. Volvox with thick cytoplasmic bridges between cells and Platydorina with flattened vegetative colonies developing via unique morphogenesis "intercalation" [7]. However, their phylogenetic positions are ambiguous even using multiple chloroplast genes [4,5], possibly due to the lack of closely related sister lineages that may represent their ancestral morphological traits. Thus, identifying the missing links may resolve these problems. Although Coleman [10] confirmed that the Eudorina cylindrica strain ASW05157 (originating from Regelsbrunn, Austria [11]) is sister to Platydorina, its morphological details were not reported; however, the internal transcriber spacer (ITS) of nuclear ribosomal DNA ( $r \mathrm{DNA}$ ) of this strain is now available (AF182439).

During our field surveys of freshwater algae in Japan, two colonial volvocalean green algae were collected from a lake. Although these algae are closely related to Platydorina in molecular phylogeny, their vegetative colonies are spheroidal in shape, resembling those of the colonial volvocine genera Yamagishiella and Eudorina (Volvocaceae) under a light microscope [12]. Notably, this new genus showed "external fertilization" between male and female gametes. Morphology, sexual reproduction, taxonomy, and phylogenetic significance of the two species of Colemanosphaera gen. nov. are described in this report.

\section{Results and discussion \\ Morphology and taxonomy}

Two species of the new colonial volvocine genus Colemanosphaera showed essentially the same colonial organization during the vegetative phase (Figure 1). Vegetative colonies were ovoid to ellipsoidal in shape in C. charkowiensis comb. nov. (Figure $1 \mathrm{~A}, \mathrm{~B}$ ) or cylindrical to elongate-ovoid in $C$. angeleri sp. nov. (Figure 1E, F). They contained 16 or 32 cells of approximately identical size embedded the peripheral regions of the gelatinous matrix, forming a hollow colonial structure. The 32-celled colonies of $C$. charkowiensis measured up to $85 \mu \mathrm{m}$ long and $67 \mu \mathrm{m}$ wide, whereas those of $C$. angeleri were up to $95 \mu \mathrm{m}$ long and $70 \mu \mathrm{m}$ wide. The

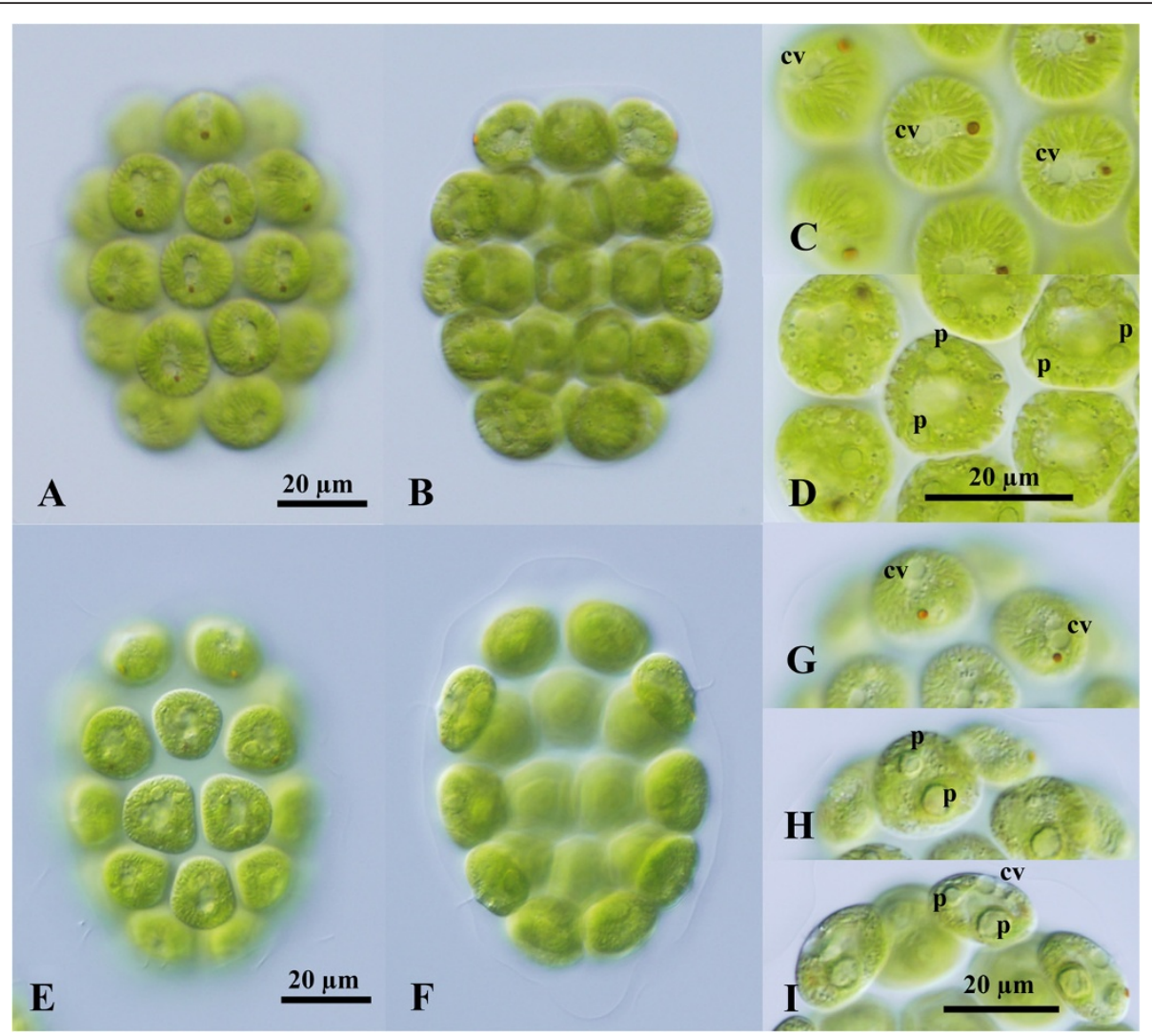

Figure 1 Light microscopy of vegetative colonies of two species of Colemanosphaera. (A)-(D) C. charkowiensis (Korshikov) Nozaki et al. comb. nov. 2013-0615-IC-7. (A), (B) Two views of a 32-celled colony shown at the same magnification. (A) Surface view. (B) Optical section. (C), (D) Two views of cells shown at the same magnification. (C) Surface view showing contractile vacuoles (cv) distributed in only the anterior end of cells. (D) Optical section. Note multiple pyrenoids (p) and strong longitudinal striations in the chloroplast periphery. (E)-(I) C. angeleri Nozaki sp. nov. 2010-0126-1.

(E), (F) Two views of a 32-celled colony shown at the same magnification. (E) Surface view. (F) Optical section. (G)-(I) Three views of cells showing contractile vacuoles (cv) and pyrenoids (p), shown at the same magnification throughout. 
cells were ovoid to subspheroidal in C. charkowiensis or subspheroidal to lenticular in C. angeleri, having a broad anterior face that was more or less angular by mutual compression, measuring up to $20 \mu \mathrm{m}$ in surface diameter in both species (Figure 1). Each cell had two equal flagella, a massive cup-shaped chloroplast, a stigma, and two or three contractile vacuoles near the base of the flagella (Figure 1C, G, I). No other contractile vacuoles were distributed on the surface of the protoplast. A gradual decrease in stigma size occurred from the anterior to posterior pole of the colony. The chloroplast contained longitudinal striations on the surface (Figure 1C, G), which were prominent in C. charkowiensis (Figure 1A-D). Although the chloroplast of both species contained only a single pyrenoid in the immature cells, three to eight pyrenoids of almost identical size were distributed throughout the chloroplast of mature vegetative cells in C. charkowiensis (Figure 1D), whereas the cup-shaped chloroplast in mature cells of $C$. angeleri contained a large single pyrenoid in the bottom, as well as one to five small pyrenoids (Figure 1H, I).

The present two species of Colemanosphaera represent vegetative and reproductive morphological attributes that are characteristic of the Volvocaceae [7,12] (Additional file 1: Figures S1 and S2; Additional file 2: Information S1), including 1) cruciate eight-celled plakea (Additional file 1: Figure S1C), 2) typical inversion during daughter colony formation (Additional file 1: Figure S1A), and 3) tripartite

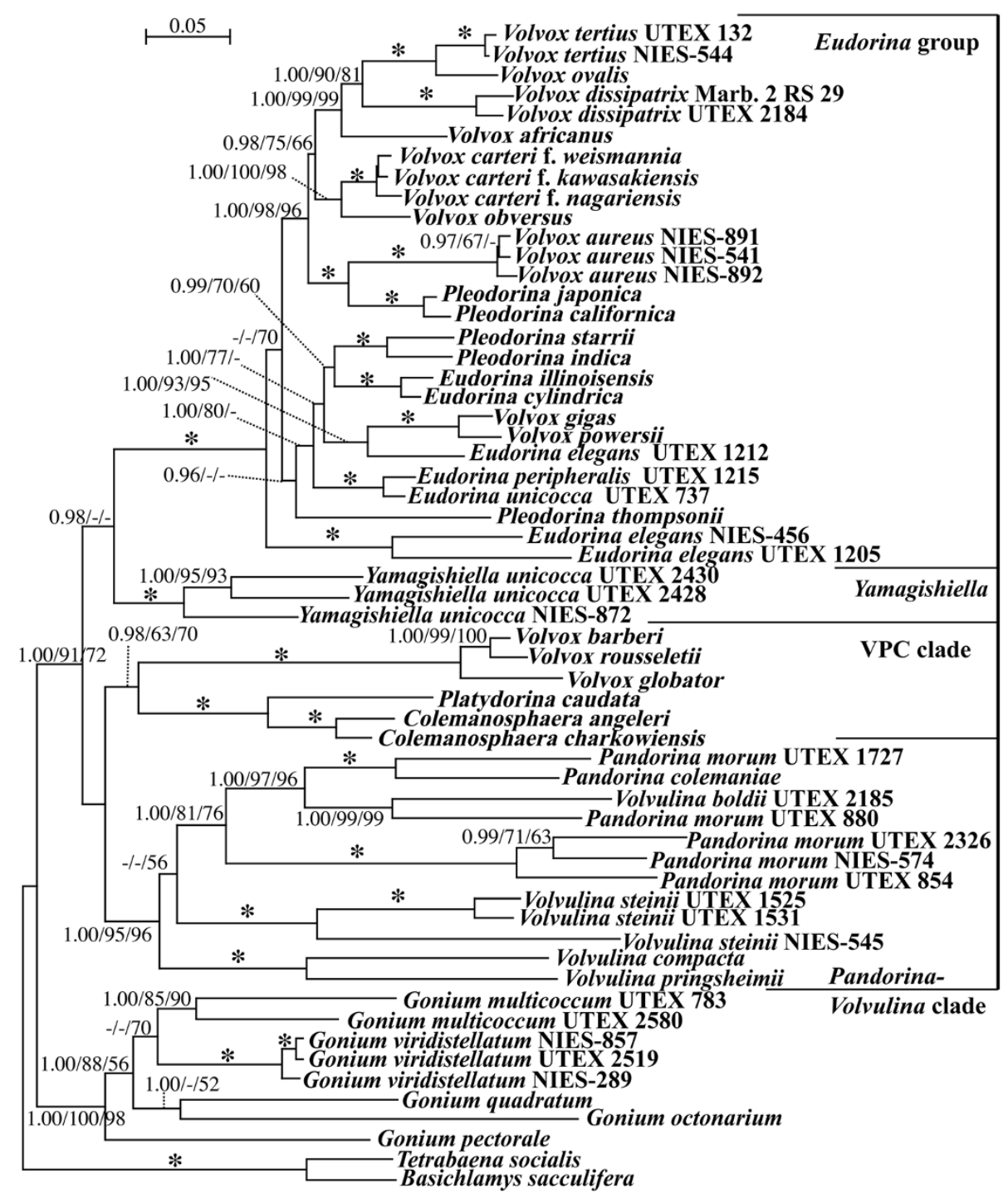

Figure 2 Bayesian inference (BI) tree of the Volvocaceae based on the chloroplast five genes. For details of the methods, see the Methods Section. Branch lengths are proportional to the genetic distances, which are indicated by the scale bar above the tree. Numbers on the left, middle, or right side at the branches represent posterior probabilities (PP) of BI $(\geq 0.95)$, bootstrap values ( $\geq 50 \%$, based on 1,000 replicates) obtained with the maximum likelihood and maximum parsimony analyses, respectively. Asterisks at the branches indicate $1.00 \mathrm{PP}$ and $100 \%$ bootstrap values by the two methods. 
colonial boundary of the extracellular matrix in vegetative colonies under transmission electron microscopy (TEM) (Additional file 1: Figure S2). In addition, the present molecular phylogeny confirmed that this new genus is robustly positioned within the Volvocaceae (Figure 2; Additional file 2: Information S1).

Within the Volvocaceae, Colemanosphaera is morphologically similar to Yamagishiella and Eudorina in having 16- or 32-celled spheroidal vegetative colonies without differentiation of obligative somatic cells, but with a cellular envelope that encompasses each vegetative cell tightly inside the colonial boundary under TEM $[12,13]$ (Additional file 1: Figure S2). However, Colemanosphaera and Yamagishiella can be clearly distinguished from Eudorina based on differences in contractile vacuoles in vegetative cells. Small contractile vacuoles are distributed on the surface of the vegetative cells of Eudorina, whereas vegetative cells of Yamagishiella and Colemanosphaera contain only two or three contractile vacuoles near the base of the flagella [14] (Figure 1). Furthermore, Colemanosphaera differed from Yamagishiella in pyrenoid characteristics and sexual reproduction. Colemanosphaera contained multiple pyrenoids in the chloroplast of mature vegetative cells and showed anisogamous sexual reproduction with sperm packets (Figures 1 and 3). Yamagishiella unicocca, the only species of the genus, was described as having a single basal pyrenoid in the chloroplast and isogamous sexual reproduction $[12,14,15]$. Therefore, Colemanosphaera is a previously undescribed morphological genus within the Volvocaceae.

The present two species of Colemanosphaera can be clearly distinguished based on differences in chloroplast morphology, development of flagellar elongation in newly formed daughter colonies, and molecular data. The chloroplast in C. charkowiensis shows prominent longitudinal striations on the surface and has more than two pyrenoids of almost identical size in mature cells, whereas $C$. angeleri has chloroplast striations that are not as prominent and contains a large basal pyrenoid and small pyrenoids in the cup-shaped chloroplast in mature cells (Figure 1). During asexual reproduction, two new flagella in each cell of a newly formed daughter colony are markedly different in

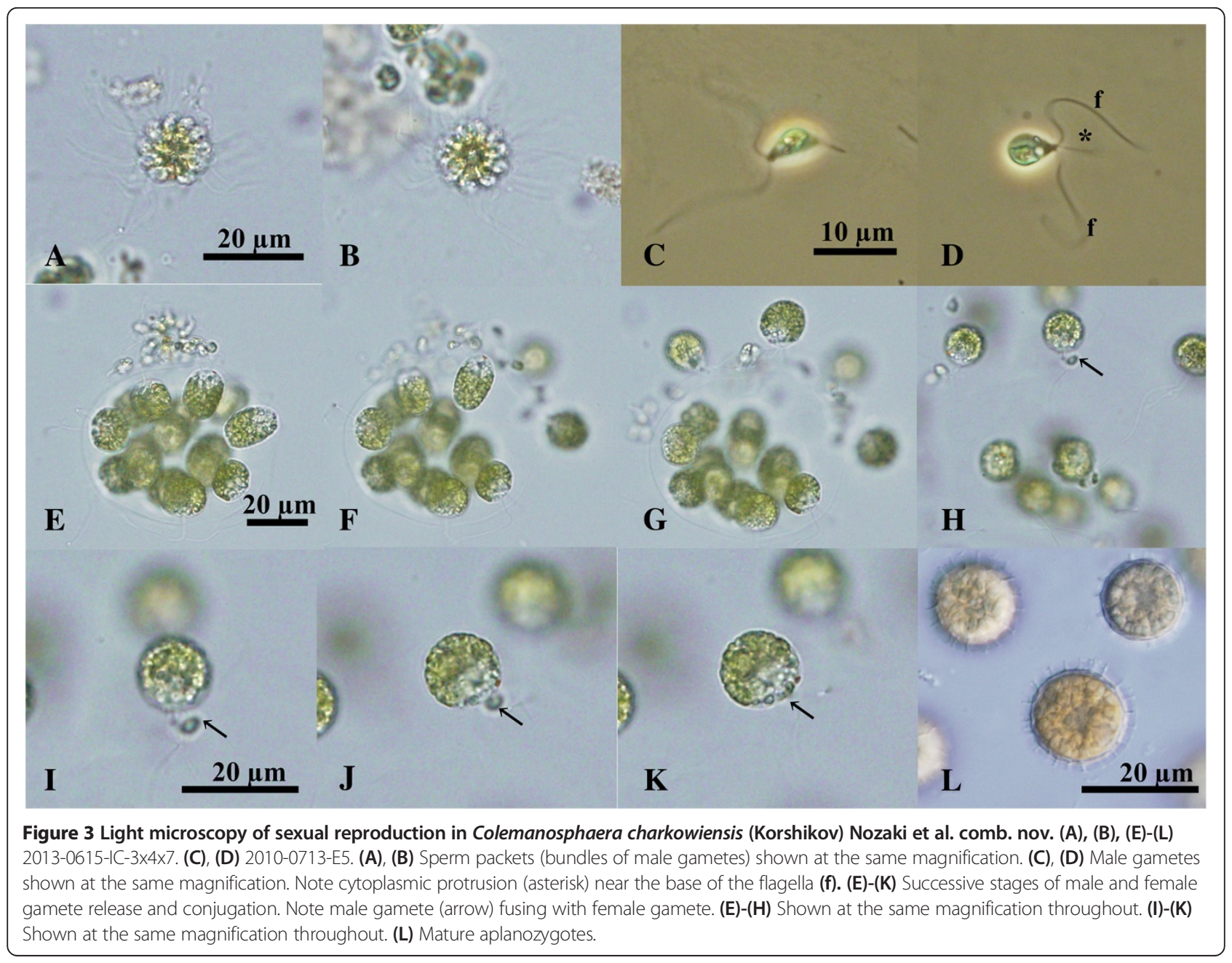


length in $C$. charkowiensis, whereas the two flagella of $C$. angeleri grow to an equal length (Additional file 1: Figure S1D, E). In addition, C. charkowiensis and C. angeleri were robustly separated from each other in the phylogenetic analysis of the ITS region of $r \mathrm{DNA}$ (Figure 4), and two compensatory base changes (CBCs) were detected in helix I and helix III of ITS-2 of the $r$ DNA between these two species (Additional file 1: Figures S3-S6; Additional file 2: Information $\mathrm{S} 1$ ). The latter $\mathrm{CBC}$ is positioned within the most conserved region of ITS-2 of $r$ DNA (the contiguous 5 '-side 30 nucleotide positions of the distal portion of helix III) [16]. According to Coleman [16], organisms that differ by even one $\mathrm{CBC}$ in this region also are completely unable to cross. Thus, the two species represent two genetically and morphologically distinct entities.

The Austrian strain ASW05157 and C. angeleri 20100126-1 formed a small clade robustly separated from $C$. charkowiensis in the phylogenetic analysis of the ITS region of $r$ DNA (Figure 4), and showed only one nucleotide difference in the ITS region (Additional file 2: Information $\mathrm{S} 1$ ). The ITS region of nuclear $r \mathrm{DNA}$ is rapidly evolving and shows nucleotide variation within a single biological species [16]. Thus, ASW05157 unambiguously belongs to C. angeleri, although its morphological data are lacking.

\section{Sexual reproduction}

Sexual reproduction was observed in C. charkowiensis (Figure 3) and generally occurred 2 days after possible male and female cultures were mixed in the nitrogen-deficient mating medium [17]. Cells of the colony divided to form a bundle of 16 or 32 male gametes or sperm packets. The packet was almost spherical in shape, measured 15-17 $\mu \mathrm{m}$ in diameter (Figure 3A, B), and swam to the female colony, which was almost indistinguishable from the vegetative colony. The packet on the female colony eventually dissociated into individual, biflagellate male gametes. The male gametes were spindle-shaped to elongate-ellipsoidal in shape and measured 5-10 $\mu \mathrm{m}$ in length. A tubular cytoplasmic protrusion was observed near the base of the flagella of the male gametes (Figure 3C, D), similar to male gametes of Eudorina elegans [18]. During dissociation of the packet, biflagellate protoplasts or female gametes escaped from the gelatinous matrix of the female colony (Figure 3E-G). Female gametes were biflagellate and spherical in shape, measuring 13-17 $\mu \mathrm{m}$ in diameter. Female and male gametes fused outside the female colony (Figure $3 \mathrm{H}-\mathrm{K})$. The anterior end of the male gamete connected the anterior region of the female gamete, and the plasmogamy proceeded to form a quadriflagellate zygote. The zygotes then lost their flagella and secreted a reticulate cell wall (Figure $3 \mathrm{~L}$ ). The zygotes eventually turned reddish brown in color after about 1 week. The mature aplanozygotes were $14-18 \mu \mathrm{m}$ in diameter (excluding reticulation).

In C. charkowiensis, male colonial cells underwent successive cell divisions to form bundles of spindle-shaped male gametes (sperm packets), whereas female gametes formed without successive cell divisions of colonial cells (Figure 3). These characteristics are essentially the same as in other members of the anisogamous/oogamous volvocacean genera Eudorina, Pleodorina, Platydorina, and Volvox [7]. However, C. charkowiensis differed from dioecious members of Eudorina, Pleodorina, and Volvox during conjugation between male and female gametes. Male and female gametic union in the latter genera takes place within the female colony after penetration by the male gametes [13,17-21]. In contrast, female gametes are released from the colonial matrix, and male and female gametes fuse outside the female colony in C. charkowiensis (Figure 3). A similar "external fertilization" between male and female motile gametes was observed in naturalcollected samples of Platydorina [22]. This type of anisogamous conjugation is similar to isogamous conjugation in Pandorina, Volvulina, and Yamagishiella in that the gametes of both sexes are released from the parental colonies [21]. In addition, the present multigene phylogeny

\subsection{5

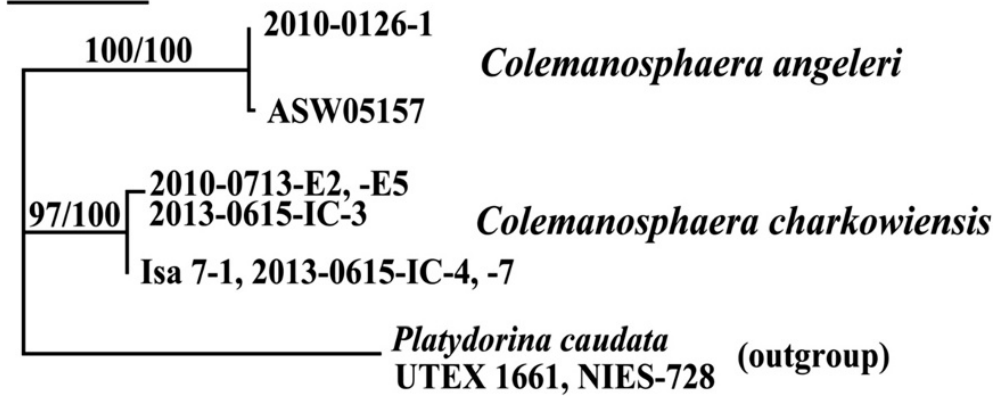

Figure 4 Maximum likelihood (ML) tree of two species of Colemanosphaera and an Austrian strain (ASW05157) based on internal transcriber spacer region of nuclear ribosomal DNA. For details of the methods, see the Methods Section. Branch lengths are proportional to the genetic distances, which are indicated by the scale bar above the tree. Numbers on the left or right side at the branches represent bootstrap values ( $250 \%$, based on 1,000 replicates) obtained with the $M L$ and maximum parsimonious analyses, respectively. 
demonstrated that Colemanosphaera and Platydorina form a robust clade that is sister to the lineage of Volvox sect. Volvox (Figures 2 and 5), which shows "internal fertilization during oogamy" [7,23]. Thus, "external fertilization during anisogamy," as found in Colemanosphaera and Platydorina, may represent an evolutionary intermediate between "external fertilization during isogamy" and "internal fertilization during anisogamy/oogamy" in the colonial volvocine green algae (Figure 5).

\section{Phylogenetic significance}

The present multigene phylogeny demonstrated that Colemanosphaera is robustly sister to the unique flattened volvocacean genus Platydorina (Figure 2). Although these genera differ in the form of their vegetative colonies (spheroidal vs. flattened, respectively), they share fundamental morphological characteristics during the vegetative phase and sexual reproduction. The vegetative colonies of both genera are composed of 16 or 32 cells of identical size $[7,22,24]$ (Figure 1). Two or three contractile vacuoles are limited to the anterior end of the vegetative cells in both genera (Figure 1; Additional file 1: Figure S7). Vegetative ultrastructures of these two genera were used to observe colonial boundaries and cellular envelopes [12] (Additional file 1: Figure S2). In addition, both genera show sperm packet formation and "external fertilization" between male and female motile gametes [22] (Figure 3). Thus, Colemanosphaera may exhibit ancestral morphological attributes of Platydorina, and a Colemanosphaeralike spheroidal colonial ancestor might have evolved to
Platydorina by acquiring intercalation to form flattened vegetative colonies during embryogenesis.

\section{Taxonomic consideration of species}

Although small contractile vacuoles are distributed on the surface of the vegetative cells of Eudorina [14], HuberPestalozzi [25] and Ettl [26] characterized the genus Eudorina as having two anterior contractile vacuoles. Thus, some Eudorina species in which contractile vacuoles have not been studied carefully may actually belong to Colemanosphaera. Among the described species of Eudorina [19,27], E. echidna and E. interconnexa have not been studied in culture. In addition, the strain of E. conradii [28] is not available from the UTEX Culture Collection (http://web.biosci.utexas.edu/utex/). However, these three species of Eudorina can be clearly distinguished from the present two species of Colemanosphaera based on differences in vegetative morphology. These three Eudorina species have almost spherical vegetative cells $[19,29,30]$. In contrast, cells of two species of Colemanosphaera are ovoid, subspheroidal, or lenticular in shape with a broad anterior face that seems more or less angular by mutual compression (Figure 1). In addition, the three species of Eudorina are characterized by distinctive vegetative colony structures [19]. E. conradii and E. interconnexa have species-specific individual gelatinous sheaths surrounding vegetative cells $[19,30]$, while E. echidna shows short conical projections covering the vegetative colony [29].

Thompson [31] observed conjugation between small male and large female gametes outside the female colony in "Pandorina charkowiensis." However, male gametes are

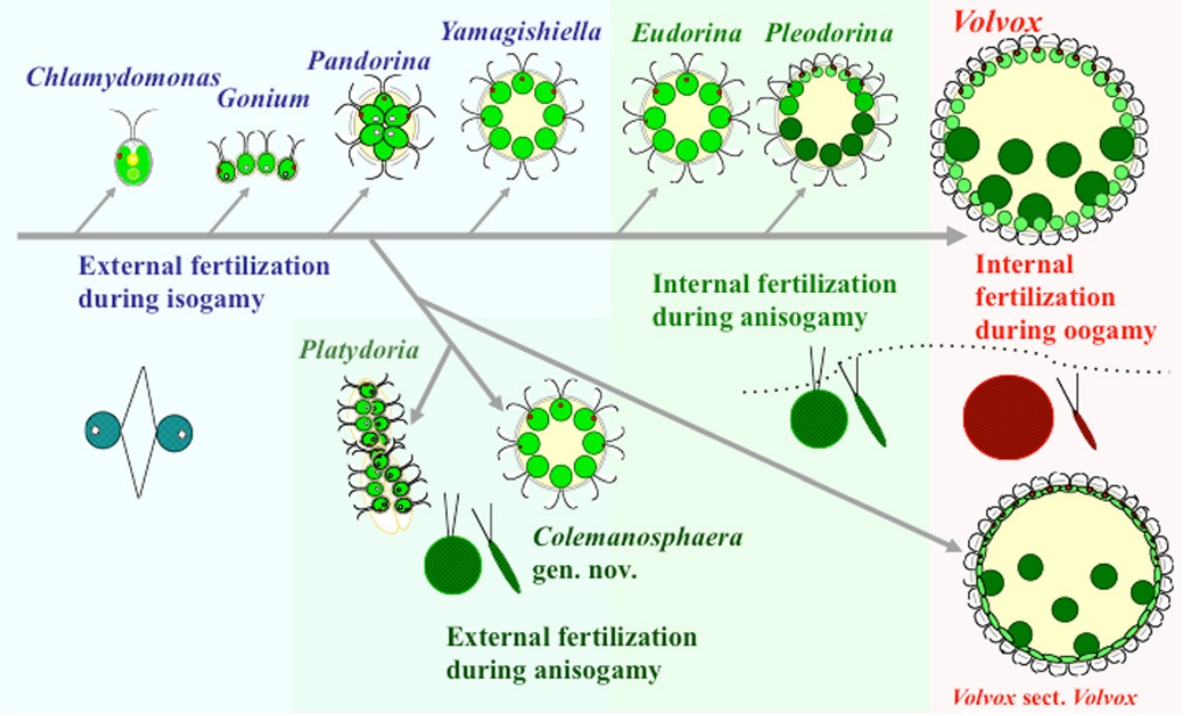

Figure 5 Diagram showing phylogeny and evolution of sexual reproduction characteristics within the colonial volvocine greens. Based on the present study. 
not elongate or spindle-shaped in this alga. Although $P$. charkowiensis contains multiple pyrenoids in the cupshaped chloroplast in each vegetative cell [32] (Figure 1), information on pyrenoids of the alga observed by Thompson [31] is lacking in his description and figures. Therefore, the alga may be Yamagishiella unicocca, in which small and large gametes can fuse [15,18].

Korshikov's description of the alga from the Ukraine that he called Pandorina charkowiensis indicates that it is highly similar in vegetative morphology to the Japanese $C$. charkowiensis strains described here, in that it has subspheroidal cells with a broad anterior face, two contractile vacuoles, and multiple (up to seven) pyrenoids in a cupshaped chloroplast with prominent longitudinal striations on its surface [32]. He did not evaluate its sexual reproduction [32], but if he had, there is little doubt that he would have found that it was not isogamous like Pandorina. On the other hand, the other Colemanosphaera species (C. angeleri) contains more flattened vegetative cells and less prominent chloroplast striations than those of C. charkowiensis (Figure 1). Thus, C. angeleri represents a previously undescribed morphological species.

\section{Conclusions}

Two species of Colemanosphaera were found in a Japanese lake (Additional file 2: Table S1). As discussed above, comparison of ITS sequences demonstrated that the Austrian strain ASW05157 unambiguously belongs to C. angeleri (Figure 4). C. charkowiensis was originally described based on material originating from Ukraine [32]. Thus, Colemanosphaera may be distributed in worldwide freshwater habitats. Although $P$. charkowiensis was reported from the United States [31,33,34], it may be $Y$. unicocca or Eudorina species because information on contractile vacuoles and/or pyrenoids is limited. Further detailed molecular and morphological studies of the Eudorina- and Yamagishiella-like colonial volvocine algae will resolve actual worldwide distribution and diversity of the new genus Colemanosphaera.

The present study unambiguously demonstrated external fertilization between male and female gametes using Colemanosphaera cultures. When such a type of gametic union is considered with previously published data [7], sexual reproduction of the volvocine green algae can be clearly distinguished into four types (with the exception of monoecism) (Figure 5): 1) External fertilization during isogamy with gametes directly released from colonial cells, 2) external fertilization during anisogamy with the formation of bundles of spindle-shaped male gametes (sperm packet formation), 3) internal fertilization during anisogamy (with flagellated female gametes retained within the parental female colony), and 4) internal fertilization during oogamy (with flagella-lacking female gametes formed within the parental female colony). Thus, oogamy evolution may have been preceded by the transition from external to internal fertilization during anisogamy within the volvocine green algae.

\section{Taxonomic treatments}

Colemanosphaera Nozaki gen. nov.

Vegetative colonies spheroidal in shape, composed of 16 or 32 cells of approximately identical sizes embedded at the peripheral regions of the gelatinous matrix forming a hollow colonial structure. The extracellular matrix of vegetative colonies exhibiting colonial boundaries and cellular envelopes. Each cell biflagellate, more or less angular in front view, containing a massive cup-shaped chloroplast, a stigma, and a nucleus. Two or three contractile vacuoles distributed near the base of the flagella. Chloroplasts containing longitudinal striations on the surface and multiple pyrenoids in mature cells. A gradual decrease in stigma size occurring from the anterior to posterior pole of the colony. Asexual reproduction accomplished by successive divisions of each vegetative cell, forming a square plakea undergoing typical inversion to produce a spheroidal daughter colony.

Type species: Colemanosphaera charkowiensis (Korshikov) Nozaki, T. K. Yamada, F. Takahashi, Matsuzaki et Nakada comb. nov.

Etymology: The generic name "Colemanosphaera" honoring Dr. Annette W. Coleman who contributed much to the species systematics of microalgae [16].

Colemanosphaera charkowiensis (Korshikov) Nozaki, T. K. Yamada, F. Takahashi, Matsuzaki et Nakada comb. nov.

Basionym: Pandorina charkowiensis Korshikov 1923 [32]: 174, pl. 7, Figure 1.

Synonym: Eudorina charkowiensis (Korshikov) Pascher 1927 [35]: 441.

Holotype: Figure 1 of pl. 7 in Korshikov [32].

Epitype here designated: Resin-embedded vegetative spheroids of 2013-0615-IC-7 (= NIES-3388) deposited in the herbarium of the Department of Botany, National Museum of Nature and Science (TNS), Tsukuba, Japan (TNS-AL-56994).

Strains examined: 2013-0615-IC-7, 2013-0615-IC-4, 2013-0615-IC-3, Isa 7-1, 2010-0713-E2, and 2010-0713E5 (Additional file 2: Table S1).

Distribution: Ukraine [32], Japan.

Colemanosphaera angeleri Nozaki sp. nov.

Vegetative colonies 16- or 32-celled, cylindrical to elongate-ovoid in shape, measuring up to $95 \mu \mathrm{m}$ long and up to $70 \mu \mathrm{m}$ wide. Cells subspheroidal to lenticular in shape, measuring up to $20 \mu \mathrm{m}$ in surface diameter. Chloroplasts in mature cells containing a large pyrenoid and one to five small pyrenoids. Two flagella in each cell of a newly formed daughter colony growing equally. Sexual reproduction not observed.

Holotype: Resin-embedded vegetative spheroids of 20100126-1 (= NIES-3382) deposited in the herbarium of the 
Department of Botany, National Museum of Nature and Science (TNS), Tsukuba, Japan (TNS-AL-56995).

Strain examined: 2010-0126-1 (Additional file 2: Table S1).

Etymology: The species epithet "angeleri" honoring Dr. David Angeler who studied the Austrian strain ASW05157 of this species [11].

Type locality: Lake Isanuma, Isanuma, Kawagoe-shi, Saitama, Japan (Additional file 2: Table S1).

Distribution: Austria [11], Japan.

\section{Methods}

Samples of Colemanosphaera were collected four times during the last several years from Lake Isanuma and its adjoining small pond, Isanuma, Kawagoe-shi, Saitama Prefecture, Japan (Additional file 2: Table S1). Clonal cultures were established using the pipette-washing method [36] either directly from water samples or from media obtained by rewetting a small amount of dried soil in a $90-\times 20-\mathrm{mm}$ Petri dish. The cultures were grown in screw-cap tubes $(18 \times 150 \mathrm{~mm})$ containing $\sim 11 \mathrm{~mL}$ of AF-6 medium [37] modified by Kasai et al. [38] or VTAC medium (containing $200 \mathrm{mg} \mathrm{L}^{-1}$ sodium acetate $\left.4 \mathrm{H}_{2} \mathrm{O}[18,38]\right)$ at $23-25^{\circ} \mathrm{C}$ on a 14-h light:10-h dark schedule under cool-white fluorescent lamps (color temperature $=4000-5000 \mathrm{~K}$ ) at an intensity of $110-150 \mu \mathrm{mol} \cdot \mathrm{m}^{-2} \cdot \mathrm{s}^{-1}$. Vegetative colonies and asexual reproduction were observed by examining a small aliquot of cells grown continuously by inoculating $\sim 0.5-1.0 \mathrm{~mL}$ of actively growing cells into fresh medium every $3-10$ days.

To induce sexual reproduction, cultures grown in the modified AF- 6 medium at about $25^{\circ} \mathrm{C}$ were concentrated from 11 to $0.5 \mathrm{~mL}$ by centrifugation. The concentrated possible male and female cultures were mixed with $10 \mathrm{~mL}$ of nitrogen-deficient "mating medium" [17] in a $60 \times 10-$ mm Petri dish.

To examine the light microscopic details and the ITS region of nuclear rDNA, Platydorina caudata UTEX 1661 and NIES-728 (= UTEX 1658) were obtained from the Culture Collection of Algae at the University of Texas at Austin [39] (http://web.biosci.utexas.edu/utex/) and Microbial Culture Collection at the Institute for National Environmental Studies [38] (http://mcc.nies.go.jp/), respectively, and they were cultured in the modified AF-6 medium as described above. Light microscopy was performed using a BX60 microscope (Olympus, Tokyo, Japan) equipped with Nomarski optics. TEM was performed using $0.8 \%$ glutaraldehyde during pre-fixation as described previously [12].

Five chloroplast genes ( $a t p B, r b c L, p s a A, p s a B$, and $p s b C$ ) and ITS region of $r$ DNA (ITS-1, 5.8S $r$ DNA, and ITS-2) of two species of Colemanosphaera and the ITS region of $P$. caudata UTEX 1661 and NIES-728 were sequenced as described previously $[3,40]$. For phylogenetic analysis of chloroplast genes, the combined coding regions of the five chloroplast genes [3] from 58 operational taxonomic units (OTUs) of the colonial volvocine algae (Additional file 2: Table S2) were subjected to Bayesian inference using MrBayes 3.2.1. [41] as described previously [42]. In addition, 1,000 replicates of bootstrap analyses [43] were performed by maximum-likelihood (ML) analysis with RAxML ver. 7.0.4 [44] using a GTR model of each codon position in the five concatenated genes unlinked and by the maximum-parsimony (MP) method using PAUP 4.0b10 [45], as described previously [46]. Because the third codon positions of the combined five genes showed heterogeneous base compositions among OTUs $(\mathrm{p}<0.01)$ based on chi-square tests of PAUP 4.0, the third codon positions of $p s a B$ genes, which seemed to have the greatest effect on the heterogeneity among the five genes, were excluded to minimize heterogeneity ( $p>$ $0.05)$. The alignment (5,525 positions and 38 OTUs) used for the present phylogenetic analyses (Figure 2) is available from TreeBASE (http://treebase.org/treebase-web/home. html; study ID: S15331).

Goniacean and tetrabaenacean OTUs were designated as the outgroup because Volvocaceae is monophyletic and sister to the Goniaceae, and these two families and the Tetrabaenaceae form a large monophyletic group [3-5]. Because the colonial volvocine Astrephomene species (Goniaceae) showed possible saturation of the chloroplast genes [3] and were positioned outside the Volvocaceae $[3,5]$, we excluded this genus.

Nucleotide sequences for the ITS region of $r$ DNA from Colemanosphaera (Additional file 2: Table S1), ASW05157, and the outgroup P. caudata UTEX 1661 and NIES-728 (accession numbers AB905587 and AB905588) were aligned using ClustalX [47]. After refining the alignment based on the secondary structures of ITS-1 and ITS-2 $[10,48]$ and reducing identical sequences to a single OTU, the alignment (676 positions and five OTUs; study ID: S15331 available from TreeBASE) were subjected to MP and ML (based on HKY85 model) methods based on a branch-and-bound search by PAUP 4.0 with bootstrap analysis based on 1,000 replicates. The secondary structures of ITS-2 were predicted based on that of Platydorina [48] and refined as described previously [49] using Centroidfold [50] and RNAfold at the RNAfold WebServer [51] (http:// rna.tbi.univie.ac.at/cgi-bin/RNAfold.cgi).

\section{Additional files}

Additional file 1: Figure S1. Light microscopy of asexual reproduction of two species of Colemanosphaera. Figure S2. Transmission electron micrographs of vegetative colony of two species of Colemanosphaera. Figure S3. Secondary structures of helix I and helix III of nuclear ribosomal DNA internal transcribed spacer 2 transcript of Colemanosphaera charkowiensis (Korshikov) Nozaki et al. comb. nov. (Isa 7-1, 2010-0713-E2, 2010-0713-E5, 2013-0615-IC-3, 2013-0615-IC-4 and 2013-0615-7), and C. angeleri Nozaki sp. nov. (2010-0126-1 and ASW05157). Figure S4. Whole secondary structure of nuclear ribosomal DNA internal transcribed spacer 2 
transcript of Colemanosphaera charkowiensis (Korshikov) Nozaki et al. comb. nov (2010-0713-E2, 2010-0713-E5 and 2013-0615-IC-3). Figure S5. Whole secondary structure of nuclear ribosomal DNA internal transcribed spacer 2 transcript of Colemanosphaera angeleri Nozaki sp. nov. (2010-0126-1 and ASW05157). Figure S6. Whole secondary structure of nuclear ribosomal DNA internal transcribed spacer 2 transcript of Platydorina caudata Kofoid UTEX 1661 and NIES-728 (=UTEX 1658). Figure S7. Light microscopy of vegetative colonies of Platydorina caudata Kofoid. NIES-728 (=UTEX 1658).

Additional file 2: Information S1. Asexual reproduction, transmission electron microscopy, molecular phylogenetic analyses, and secondary structures of ITS-2 rDNA. Table S1. List of strains of Colemanosphaera used in this study. Table S2. List of the colonial volvocine taxa/strains included in the phylogenetic analysis (Figure 2) and DDBJ/EMBL/GenBank accession numbers of the five chloroplast genes.

\section{Abbreviations}

BI: Bayesian inference; CBC: Compensatory base changes; ITS: Internal transcriber spacer; ML: Maximum likelihood; MP: Maximum parsimony: OTU: Operational taxonomic unit; rDNA: Ribosomal DNA; TEM: Transmission electron microscopy

\section{Competing interests}

The authors declare that they have no competing interests.

\section{Authors' contributions}

HN, TKY and FT conducted the morphological and molecular biology experiments. HN, RM and TN constructed phylogenetic trees and secondary structures of nuclear ITS2. HN and RM wrote the manuscript. All authors read and approved the manuscript.

\section{Acknowledgements}

This work was supported by Grants-in-Aid for Scientific Research on Innovative Areas "Allogeneic Authentication" (grant number 24112707 to $H N$ ), and Scientific Research (B) (grant number 25304012 to HN) from MEXT/ JSPS KAKENHI.

\section{Data depositions}

All new sequences have been deposited to DDBJ/EMBL/GenBank (accession numbers: AB905580 - AB905598). Sequence alignments of the five chloroplast genes and the ITS region of nuclear rDNA have been deposited in TreeBASE (study ID: S15331).

\section{Author details}

${ }^{1}$ Department of Biological Sciences, Graduate School of Science, University of Tokyo, 7-3-1 Hongo, Bunkyo, Tokyo 113-0033, Japan. ${ }^{2}$ College of Life Sciences, Ritsumeikan University, 1-1-1 Noji-higashi, Kusatsu, Shiga 525-8577, Japan. ${ }^{3}$ Institute for Advanced Biosciences, Keio University, 246-2 Mizukami, Kakuganji, Tsuruoka, Yamagata 997-0052, Japan. ${ }^{4}$ Systems Biology Program, Graduate School of Media and Governance, Keio University, Endo 5322, Fujisawa, Kanagawa 252-0882, Japan.

Received: 18 December 2013 Accepted: 25 February 2014 Published: 3 March 2014

\section{References}

1. Sachs JL: Resolving the first steps to multicellularity. Trends Ecol Evol 2008, 23:245-248

2. Hiraide R, Kawai-Toyooka H, Hamaji T, Matsuzaki R, Kawafune K, Abe J, Sekimoto H, Umen J, Nozaki H: The evolution of male-female sexual dimorphism predates the gender-based divergence of the mating locus gene MAT3/RB. Mol Biol Evol 2013, 30:138-140.

3. Nozaki H, Misawa K, Kajita T, Kato M, Nohara S, Watanabe MM: Origin and evolution of the colonial Volvocales (Chlorophyceae) as inferred from multiple, chloroplast gene sequences. Mol Phylogenet Evol 2000, 17:256-268.

4. Nozaki $\mathrm{H}$ : Origin and evolution of the genera Pleodorina and Volvox (Volvocales). Biologia 2003, 58(4):425-431.

5. Herron MD, Hackett JD, Aylward FO, Michod RE: Triassic origin and early radiation of multicellular volvocine algae. Proc Natl Acad Sci USA 2009, 106:3254-3258.
6. Weise L: Genetic aspects of sexuality in Volvocales. In Genetics of Algae. Edited by Lewin RA. Oxford: Blackwell; 1976:174-197.

7. Nozaki H, Ito M: Phylogenetic relationships within the colonial Volvocales (Chlorophyta) inferred from cladistic analysis based on morphological data. J Phycol 1994, 30:353-365.

8. Nozaki H, Mori T, Misumi O, Matsunaga S, Kuroiwa T: Males evolved from the dominant isogametic mating type. Curr Biol 2006, 16:R1018-R1020.

9. Ferris P, Olson BJ, De Hoff PL, Douglass S, Casero D, Prochnik S, Geng S, Rai R, Grimwood J, Schmutz J, Nishii I, Hamaji T, Nozaki H, Pellegrini M, Umen JG: Evolution of an expanded sex-determining locus in Volvox. Science 2010, 328:351-354.

10. Coleman AW: Phylogenetic analysis of "Volvocacae" for comparative genetic studies. Proc Natl Acad Sci USA 1999, 96:13892-13897.

11. Angeler DG, Schager $M$, Coleman AW: Phylogenetic relationships among isolates of Eudorina species (Volvocales, Chlorophyta) inferred from molecular and biochemical data. J Phycol 2002, 35:815-823.

12. Nozaki H, Kuroiwa T: Ultrastructure of the extracellular matrix and taxonomy of Eudorina, Pleodorina and Yamagishiella gen. nov. (Volvocaceae, Chlorophyta). Phycologia 1992, 31:529-541.

13. Nozaki H, Ott FD, Coleman AW: Morphology, molecular phylogeny and taxonomy of two new species of Pleodorina (Volvoceae, Chlorophyceae). J Phycol 2006, 42:1072-1080.

14. Yamada TK, Miyaji K, Nozaki H: A taxonomic study of Eudorina unicocca (Volvocaceae, Chlorophyceae) and related species, based on morphology and molecular phylogeny. Eur J Phycol 2008, 43:317-326.

15. Rayburn WR, Starr RC: Morphology and nutrition of Pandorina unicocca sp. nov. J Phycol 1974, 10:42-49.

16. Coleman AW: Is there a molecular key to the level of "biological species" in eukaryotes? A DNA guide. Mol Phylogenet Evol 2009, 50:197-203.

17. Nozaki H, Kuroiwa H, Mita T, Kuroiwa T: Pleodorina japonica sp. nov. (Volvocales, Chlorophyta) with bacteria-like endosymbionts. Phycologia 1989, 28:252-267.

18. Nozaki H: Sexual reproduction in Eudorina elegans (Chlorophyta, Volvocales). Bot Mag Tokyo 1983, 96:103-110.

19. Goldstein M: Speciation and mating behavior in Eudorina. J Protozool 1964, 11:317-344.

20. Nozaki H: Morphology, sexual reproduction and taxonomy of Volvox carteri f. kawasakiensis f. nov. (Chlorophyta) from Japan. Phycologia 1988 27:209-220

21. Nozaki H: Morphology and evolution of sexual reproduction in the Volvocaceae (Chlorophyta). J Plant Res 1996, 109:353-361.

22. Taft CE: Asexual and sexual reproduction in Platydorina caudata Kofoid. Trans Am Microscop Soc 1940, 59:1-11.

23. McCracken MD, Starr RC: Induction and development of reproductive cells in the K-32 strains of Volvox rousseletii. Arch Protistenk 1970, 112:262-282.

24. Harris DO, Starr RC: Life history and physiology of reproduction of Platydorina caudata Kofoid. Arch Protistenk 1969, 111:138-155.

25. Huber-Pestalozzi G: Das Phytoplankton des Süßwassers: Systematik und Biologie. Teil 5. Chlorophyceae (Grünalgen) Ordnung: Volvocales. In Die Binnengewasser, Volume 5. 16th edition. Edited by Thienemann A. Stuttgart: E. Schweizerbart'sche Verlagsbuchhandlung; 1961:744. 158 pls.

26. Ettl H: Chlorophyta I. Phytomonadia. In Süßwasserflora von Mitteleuropa, Volume 9. Edited by Ettl H, Gerloff J, Mollenhauer D. Stuttgart: Gustav Fischer Verlag; 1983:807.

27. Nozaki H, Krienitz L: Morphology and phylogeny of Eudorina minodii (Chodat) Nozaki et Krienitz, comb. nov. (Volvocales, Chlorophyta) from Germany. Eur J Phycol 2001, 36:23-28.

28. Starr RC, Zeikus JA: UTEX-The Culture Collection of Algae at The University of Texas at Austin. J Phycol 1987, 23:1-47.

29. Swirenko DO: Über einige neue und interssante Volvocineae aus dem Suden der Ukraine. Arch Protistenk 1926, 55:191-196.

30. Prescott GW: Algae of the Panama Canal and its Tributaries. I. Flagellated organisms. Ohio J Sci 1955, 55:99-121.

31. Thompson RH: Studies in the Volvocales. I. Sexual reproduction of Pandorina charkowiensis and observations on Volvulina steinii. Am J Bot 1954, 41:142-145.

32. Korshikov AA: O dvukh novykh organizmakh iz gruppy Volvocales. Arkh Russk Protistol Obshch 1923, 2:170-178.

33. Whitford LA: New and little known algae from North Carolina. J Elisha Mitchell Sci Soc 1936, 52:93-98. pl. 12. 
34. Smith GM: Notes on the Volvocales - I-IV. Bull Torrey Bot Club 1930, 57:359-370. pls. 17-18.

35. Pascher A: Die Süswasser-Flora Deutschlands, Österreichs und der Schweiz. Heft 4: Volvocales = Phytomonadines. Flagellatae IV = Chlorophyceae I. Jena: Verlag von Gustav Fischer; 1927.

36. Pringsheim EG: Pure cultures of algae. Cambridge: Cambridge University Press; 1946.

37. Kato S: Laboratory culture and morphology of Colacium vesiculosum Ehrb. (Euglenophyceae). Jpn J Phycol 1982, 30:63-67 (in Japanese with English abstract)

38. Kasai F, Kawachi M, Erata M, Mori F, Yumoto K, Sato M, Ishimoto M (E): NIES-Collection. List of Strains. 8th Edition. Jpn J Phycol 2009, 57(1):1-350. pls. 1-7.

39. Starr RC, Zeikus JA: UTEX-The Culture Collection of Algae at The University of Texas at Austin. J Phycol 1993, 29:1-106.

40. Nozaki H, Coleman AW: A new species of Volvox sect. Merrillosphaera (Volvocaceae, Chlorophyceae) from Texas. J Phycol 2011, 47:673-679.

41. Ronquist F, Teslenko M, van der Mark P, Ayres DL, Darling A, Höhna S, Larget B, Liu L, Suchard MA, Huelsenbeck JP: MrBayes 3.2: Efficient Bayesian phylogenetic inference and model choice across a large model space. Syst Biol 2012, 61:539-542.

42. Nakada T, Tomita M, Nozaki H: Volvulina compacta (Volvocaceae, Chlorophyceae), new to Japan, and its phylogenetic position. J Jpn Bot 2010, 85:364-369.

43. Felsenstein J: Confidence limits on phylogenies: an approach using the bootstrap. Evolution 1985, 39:783-791.

44. Stamatakis A, Ludwig T, Meier H: RAxML-IIl: a fast program for maximum likelihood-based inference of large phylogenetic trees. Bioinformatics 2005, 21:456-463.

45. Swofford DL: PAUP* 4.0: Phylogenetic Analysis Using Parsimony, version 4.0610. Sunderland: Computer program distributed by Sinauer Associates; 2002.

46. Nozaki H, Nakada T, Watanabe S: Evolutionary origin of Gloeomonas (Volvocales, Chlorophyceae), based on ultrastructure of chloroplasts and molecular phylogeny. J Phycol 2010, 46:195-201.

47. Thompson JD, Gibson TJ, Plewniak F, Jeanmougin F, Higgins DG: The CLUSTAL_X windows interface: flexible strategies for multiple sequences alignment aided by quality analysis tools. Nucleic Acid Res 1997, 25:4876-4882.

48. Mai JC, Coleman AW: The internal transcribed spacer 2 exhibits a common secondary structure in green algae and flowering plants. J Mol Evol 1997, 44:258-271.

49. Matsuzaki R, Nakada T, Hara Y, Nozaki H: Description of Chloromonas kasaiae sp. nov. (Volvocales, Chlorophyceae), based on comparative electron microscopy and molecular data. Phycologia 2013, 52:239-245.

50. Hamada M, Kiryu H, Sato K, Mituyama T, Asai K: Prediction of RNA secondary structure using generalized centroid estimators. Bioinformatics 2009, 25:465-473.

51. Gruber AR, Lorenz R, Bernhart SH, Neuböck R, Hofacker IL: The Vienna RNA Websuite. Nucleic Acid Res 2008, 36:W70-W74.

doi:10.1186/1471-2148-14-37

Cite this article as: Nozaki et al:: New "missing link" genus of the colonial volvocine green algae gives insights into the evolution of oogamy. BMC Evolutionary Biology 2014 14:37.

\section{Submit your next manuscript to BioMed Central and take full advantage of:}

- Convenient online submission

- Thorough peer review

- No space constraints or color figure charges

- Immediate publication on acceptance

- Inclusion in PubMed, CAS, Scopus and Google Scholar

- Research which is freely available for redistribution

Submit your manuscript at www.biomedcentral.com/submit
C Biomed Central 